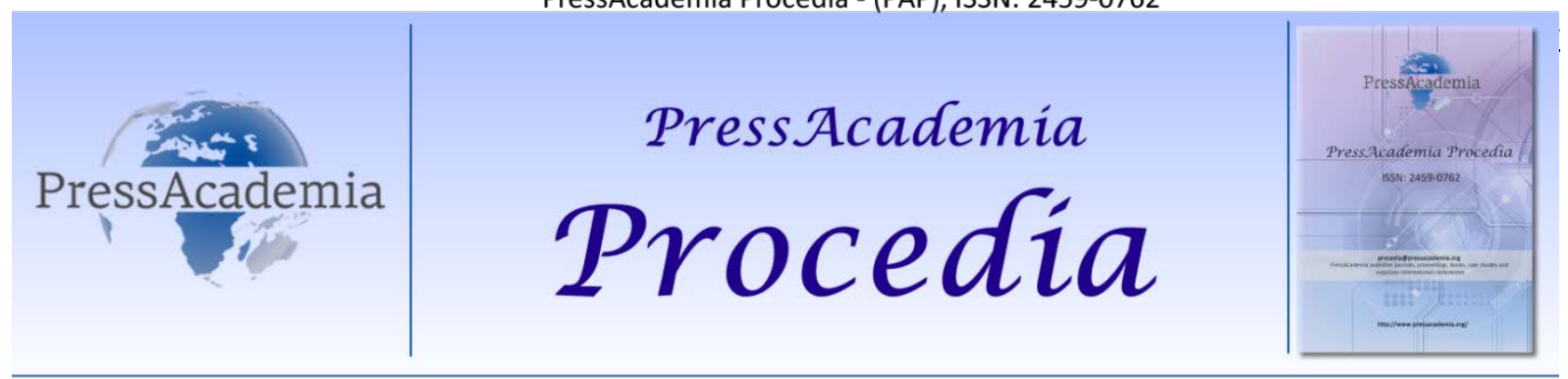

Global Business Research Congress (GBRC), May 26-27, 2016, Istanbul, Turkey.

\title{
A STUDY ON ADAPTATION OF RAILWAY MANAGEMENT COMPETITION MODELS FOR TURKEY
}

DOI: 10.17261/Pressacademia.2016118693

Ahmet Ertugrul Doludeniz

Gazi Üniversitesi, ertugruldoludeniz@gmail.com

\begin{abstract}
Railways are in the human life for over 200 years and they are directly related to the socio-economic conditions of the country. The transport sector has played a key role until the end of the Second World War. With the development of machinery industry, motor vehicles created an alternative way for the transportation and it putted and end to the superiority of railways. However, countries try to revive railway sector due to the economic reasons. This studying discussed the scope of the industry's restructuring efforts and examined the work carried out reforms. In line with these studies, opening the Turkey's railway sector into competition and presents views on the creation of a suitable model were investigated.
\end{abstract}

Keywords: Railways competiton, railway management, vertical separation

JEL Codes: L90, L91L, L92, P21, P25

DEMIRYOLU işLETMECILIĞi REKABET MODELLERININ TÜRKIYE' YE UYARLANMASI ÜZERINE BIR ÇALIŞMA

\section{ÖZET}

Demiryolları, iki yüz seneyi aşkın bir süredir insan hayatının içindedir ve ülkelerin sosyo-ekonomik koşulları ile doğrudan ilintilidir. Sektör ikinci dünya savaşının sonuna kadar taşımacılıkta kilit rol üstlenmiştir. Lakin makine endüstrisinin gelişmesi ile birlikte motorlu taşıtlar demiryollarının taşımacılık alanındaki konumuna alternatif oluşturmuş ve demiryollarının bu alandaki üstünlüğüne son vermiştir. Bununla birlikte demiryollarının karayollarına oranla daha ekonomik bir ulaştırma türü olması nedeniyle, ülkeler sektörü yeniden canlandırma girişimlerine başlamışlardır. Bu çalışma kapsamında sektörün yeniden yapılandırılma çalışmaları ele alınmış, yürütülen reform çalışmaları incelenmiş, bu çalışmalar doğrultusunda Türkiye' de demiryolu sektörünün rekabete açılması ve uygun modelin oluşturulması konusunda görüşler sunulmuştur.

Anahtar Kelimeler: Demiryollarında rekabet, demiryolu işletmeciliği, dikey yapılanma

JEL Kodları: L90, L91, L92,P21, P25

\section{GíRiş}

Türkiye gerek coğrafi gerekse fiziki konumu nedeniyle ulaştırma etkinliklerinde stratejik bir konuma sahiptir. Ulaştırma etkinliklerinde 2014 yılı verilerine göre yük taşımacılığında karayolu \% 89,5 denizyolu \% 5,9, 
demiryolu \% 4,6, yolcu taşımacılığında ise karayolu $\%$ 89,8, denizyolu $\%$ 0,6, demiryolu $\% 1,1$ ve havayolu $\% 8,5$ değerinde taşıma hacimlerine sahiptir.

Yukarıdaki rakamlardan da görüleceğe üzere taşımacılık sektöründe karayolunun bariz bir üstünlüğü bulunmaktadır. Bu durum geçmişten bu yana gelen yanlış ulaştırma politikaları ve uygulamalarından kaynaklanmaktadır. Cumhuriyetin ilk yıllarında demiryolu ağırlıklı ulaştırma politikası bırakılmış 1950 li yıllardan itibaren karayolu endeksli ulaştırma politikasına geçilmiştir. Demiryoluna oranla daha pahalı bir ulaştırma sistemini merkezine alan Türkiye, sanayi ve ekonomi alandaki büyümesi yavaşlamış, insanların yaşam kalitesinde düşüşler gözlemlenmiştir.

İkinci dünya savaşından çıkan Avrupa da aynı sonuçlar gözlemlenmiş demiryolu sektörü orada da gittikçe önemini yitirmiştir, savaştan çıkan Avrupa devletlerindeki arz - talep dengesindeki bozulmalar ve karayoluna endeksli politikalar yüzünden demiryollarının hizmet düzeyinde düşüşler yaşanmıştır. Demiryolu sektörü, büyüyen Avrupa ekonomisinin isteklerine cevap verememiş ve çağın gereksinimlerine ayak uyduramamıştır.

1960 Iı yıllara gelindiğinde petrolün insan hayatındaki etkisi o kadar büyük olmuştur ki; ulaştırmadan temel gıdalara kadar petrolün varil fiyatındaki artış ve azalışlar ülke ekonomilerini ciddi şekilde etkilemiş, ülkelerin kendi ulaştırma politikalarını yeniden gözden geçirmelerine neden olmuştur. Bu anlamda devletler demiryollarına tekrar önem vermeye başlamış ve sektörde belirli yeniden yapılanmaya gidilmiştir.

Sektördeki bu yapılanma kapsamında özel şirketlerin sektöre girişi teşvik edilmiş bu sayede demiryollarının diğer ulaştırma türleri ve kendi içindeki rekabeti sağlaması hedeflenmiştir.

Türkiye deki demiryolu sektörünün yeniden yapılandırılmasına yönelik planlama çalışmaları Devlet Planlama Teşkilatının her beş yıllık kalkınma planlarında yapılmış fakat gerçekleşme oranları çok düşük seviyelerde kalmıştır. 1995 yılından itibaren AB Müktesebatına Uyum Programı çerçevesinde AB demiryolu mevzuatıyla eşdeğer bir hukuki yapı sağlamak için yasa taslakları hazırlanmaya başlanmıştır. Bu kapsamda serbestleşmesi planlanan demiryolları için düzenleyici kurum olarak Bakanlar kurulunca 26.09.2011 tarihinde alınan karar ile Ulaştırma, Denizcilik ve Haberleşme Bakanlı̆̆ı'nın Teşkilat ve Görevleri Hakkında Kanun Hükmünde Kararname ile Demiryolu Düzenleme Genel Müdürlüğü' nün (DDGM) kurulmasına karar verilmiş 01.11.2011 tarihli ve 28102 sayılı resmi gazetede yayımlanarak yürürlüğe girmiştir. Daha sonra 1.5.2013 tarihli ve 28634 sayılı Resmi Gazete' de yayım-lanarak, 24.4.2013 tarihli 6461 sayılı Türkiye Demiryolu Ulaştırmasının Serbestleştirilmesi Hakkında Kanun yürürlüğe girmiştir. Böylece demiryollarının rekabete açılması için hukuki alt yapı tamamlanmış, uygulama aşamasına geçilmeye başlanmıştır.

Bu çalışma kapsamında; Dünya genelinde demiryolu sektörünün yeniden yapılandırılması amacıyla yapılan çalışmalar ve yöntemler incelenmiş, sektörün rekabete açılabilmesi için mevcut modeller ele alınmış ve Türkiye için en uygun modelin seçimi yönünde görüş beyan edilmiştir. Ayrıca Dünya ve Türkiye demiryolu yük taşımacılığı sektörünün mevcut yapısı incelenmiş, gelecek senelerdeki olası senaryolar ele alınmıştır.

\section{LITERATÜR TARAMASI}

\subsection{Demiryolu İşletmeciliği}

Demiryolu taşımacılığının ana altyapı bileşenleri, raylı sistemler ve donanım ürünleri ile çeken ve çekilen araçlar, aktarma istasyonları ve terminallerdir. Demiryolu taşımacılığında bu altyapı araçları bir hayli maliyetlidir ve de arazi yapısına göre maliyetler değişmektedir. Yüksek altyapı maliyetlerinden dolayı aynı güzergâhta birden fazla hattın bulunması ekonomik açıdan verimli olmadığından ve batık maliyet riski fazla olduğundan demiryolu sektörü doğal tekel özelliği arz etmektedir(Kabasakal ve Solak,2009).

Demiryolu taşımacılığı diğer taşıma modları ile kıyaslandığında kendine özgü sorunlarının olduğu görülecektir. Bunlar; sektörün çok ürünlü yapısı, demiryolu firmalarının özel maliyet yapısı, altyapısının ekonomik tesiri, girdi ve çıktıların bölünmezliği, kamu hizmeti boyutu ve bir bütün olarak alınan ulaştırma sisteminde dışsalıklar olarak karşımıza çıkmaktadır (Cantos ve Campos,2005).

Yakın zamana kadar pek çok devlette, demiryolu altyapı yatırımları kamu tarafından gerçekleştirilmiş olup özel işletmecilerin sektöre girişine izin vermeyecek şekilde işletmecilik etkinlikleri yine kamu tarafından tekel olarak 
düzenlenmiştir. Kamu işletmeciliğinin tercih edilmesinin nedeni yüksek altyapı maliyetleri ile birlikte demiryolu yolcu taşımacılığının kısa bir zamana kadar kamu hizmeti olduğu anlayışıdır. Rekabet ortamının oluşmamasından dolayı verimli işletme yapısına ulaşamayan demiryolları, işletme zararları nedeniyle kamu tarafından sürekli desteklenen bir sektör konumundadır (Ozcan,2006).

Kamu kuruluşlarının işlettiği demiryolu sektörünün desteklenme ihtiyacının giderek artması nedeniyle yeni yatırımlar için sermaye sıkıntısı çekilmeye başlanmıştır. Demiryolu sektörünün diğer taşıma türleri karşısında azalan pazar payı, devletleri yapısal değişim politikaları uygulamaya yönelmiş ve 1960 lı yıllardan bu yana birçok ülkede demiryolu sektöründe yeniden yapılanmaya gidilmiştir (Kabasakal ve Solak,2009; Ozcan,2006).

Gelişmiş ülkelerde sektörü serbestleştirme çalışmaları devam etmek ile birlikte özel girişimcilerin demiryollarından etkin bir biçimde yararlanmaları amaçlanmaktadır. Örneğin şirketler kendi demiryolu hatlarını inşa ederek üretim noktaları ile dağıtım noktaları arasında bağlantı kurmaktadırlar. Birleşme hatları ile yük vagonları, işletmelere veya depoların içlerine kadar ulaşmaktadır. Bu sayede sevk edilecek mallar, trenlere üretildikleri noktada yüklenebilmekte; fabrika, firma ve organize sanayi bölgelerinin üretim ve hammadde sevkiyatında ara nakliye yolları ortadan kaldırımaktadır bu sayede gerek zaman gerekse maliyet açısından kazanım sağlanmaktadır (Bayraktutan ve Özbilgin, 2014).

Kamu kaynakları tarafından yapılan altyapı yatırımlarında özel şirketlerin işletmecilik faaliyetleri, şirketlerin kendi vagonları ya da kiraladıkları vagonlarla demiryollarında yük taşımacılığı yapılması ile olmaktadır (Bayraktutan ve Özbilgin, 2014).

Kanada, ABD, Meksika gibi ülkelerde firmalar demiryolu altyapılarını kendileri inşa etmektedirler. Bu sayede üretim noktaları ile dağıtım noktaları arasında bağlantı kurarlar. İltisak hatları ile yük vagonları, işletmelere veya depoların içlerine kadar ulaştırılmaktadır, böylece sevk edilecek mallar, trenlere üretildikleri noktada yüklenebilmekte; fabrika, firma ve organize sanayi bölgelerinin üretim ve hammadde sevkiyatında ara nakliye yolları ortadan kaldırılmakta; demiryollarının kazanımları güçlendirilmektedir (Kabasakal ve Solak,2009; Bayraktutan ve Özbilgin, 2014).

\subsubsection{Demiryolu Taşımacılığının Diğer Taşıma Türlerine Göre Avantajları}

- Demiryolu taşımacılığının sağlayacağı avantajlar aşağıda belirtilmiştir. Bunlar:

- Ulaşımda özel araçlara olan eğilimi azaltması,

- Kentlerde trafik akışındaki sıkışıklığı gidermesi,

- Sürdürülebilir kent içi ulaşımını sağlaması,

- Kentlerde yaşam kalitesini ve kentlerin çekiciliğini artırması,

- Taşımacılıkta emniyet ve güvenliği artırması,

- Yurtiçi taşımalarda karayolu taşımacılığının aldığı payı azaltması,

- Karayolunda araç yoğunluğunun zayıflatmasıyla çevre üzerindeki olumsuz etkileri azaltması,

- Taşımacılıkta enerji tüketimini en aza indirmesi,

- Ulaştırma üzerindeki kontrol ve denetim faaliyetlerini kolaylaştırması,

- Yük aktarma ve teslim sürelerini rekabetçi boyutlara düşürmesi,

- Lojistik sektörünün rekabetçi gücünü artırması,

- Taşımacılığın düşük maliyetli ve güvenli olması,

- Taşıma hacminin yüksek olması,

- Trafik sorununun olmaması,

- Olumsuz hava koşullarından en az oranda etkilenmesi, 
- Çevreye duyarlı bir taşımacılık türü olması

- Diğer taşıma türlerinin aksine uzun dönem sabit fiyat garantisi vermesi,

- Sefer sürelerinin sabit olması,

- Uluslararası geçişlerde kara yolunda geçiş sınırlamaları bulunurken transit ülkelerin tercih ettiği bir taşıma türü olmasından dolayı geçiş üstünlüğü verilmesidir. (MEB,2011).

Karayolu ile taşınması olası olmayan 500 ton ile 3000 ton arası yükler blok trenler ile taşınabilmektedir. Örnek verilecek olursa 100 araçlık bir kamyon konvoyunun yükünü taşıyabilen yük trenleri, aynı zamanda kaza riskini de azaltmaktadır (Bayraktutan ve Özbilgin, 2014).

Taşımacılık hizmeti veren firmanın içsel maliyetleri ile gürültü, çevre kirliliği, trafik tıkanıklığı gibi dışsal maliyetlerin toplamına bakacak olursak, demiryolu taşımacılığı diğer taşımacılık türlerine oranla daha az marjinal maliyete yol açtığı görülecektir. Tablo 1 de, aynı güzergah üzerinde hareket halindeki bir tren ve bir kamyonun $346 \mathrm{~km}$ boyunca taşıma faaliyeti esnasındaki marjinal maliyetlerinin karşılaştırılması gösterilmektedir (Bayraktutan ve Özbilgin, 2014; McCullough,2006).

Demiryolu yük taşımacılığında ilk yatırım maliyetleri yüksek olmakla beraber, işletme maliyetleri karayolu taşımacılığına oranla daha düşük, taşıma kapasitesi ve kullanım ömrü daha yüksek; kaza riskleri, enerji tüketimi, trafik sıkışıkığı ve personel istihdamı ise daha azdır. Demiryolu yük taşımacılığının iktisadi fayda yaratma potansiyelinin oldukça yüksek olduğu bilinmektedir (Şenlik,2013).

Tablo 1: Kamyon ve tren marjinal maliyetleri (Bayraktutan ve Özbilgin, 2014)

\begin{tabular}{lrrr}
\hline Kategoriler & Kamyon & Tren \\
\hline Tıkanıklık & 6,25 & 0 \\
\hline Kaza & 26,11 & 9,19 \\
\hline Çevre kirliliği & 6,75 & 1,43 \\
\hline Enerji Tüketimi & 3,63 & 0,39 \\
\hline Gürültü & 0 & 0,78 \\
\hline Altyapı yıpranma payı & 61,02 & 0 \\
\hline Taşıyıcı maliyeti & 427,94 & 113 \\
\hline Toplam & 531,7 & 124,87 \\
\hline
\end{tabular}

\subsubsection{Demiryolu Taşımacılığının Diğer Taşıma Türlerine Göre Dezavantajları}

Demiryolu taşımacılığının avantajları olduğu gibi aynı zamanda dezavantajları da vardır fakat bunlar avantajları ile kıyaslandığında oldukça az seviyede kalır.

Demiryolu taşımacılığının dezavantajları aşağıda belirtildiği şekildedir:

- Transit süreleri bazı teslim bölgelerinde kara yolu ve deniz yoluna göre daha uzun zaman alabilmektedir,

- Özellikle Türkiye içindeki parkurda, teslimat daha uzun sürelerde yapılabilmektedir,

- Kapıdan kapıya teslimlerde Avrupa'da çoğu yerlerde fabrika içine kadar ray bağlantısı olmasına rağmen, Türkiye'de bu imkân yok denecek kadar azdır,

- Kapıdan kapıya teslimlerde çoğu yerde tren en yakın istasyona kadar gelebilmekte, fakat teslim adresi için ayrıca kamyon aktarmasına gereksinim duyulmaktadır,

- Taşınacak yük miktarı, vagon sayısı ve vagon büyüklüğünün yanı sıra yeryüzü şekillerine bağlı olarak belirlenmektedir, 
- Demiryolu taşımacılığının güzergâh değiştirme konusunda esnekliğe sahip olmaması ile başlangıç noktasından varış yerine kadar aktarmasız bir taşımaya olanak vermemektedir (MEB,2011).

\subsection{Demiryollarında Rekabet ve Reform Çalışmaları}

Demiryolları zamanla içinde bulunduğu ulaştırma piyasasındaki rekabetin bir parçası olmaktan uzaklaşmıştır. 20. yy başlarındaki ekonomik krizlerle birlikte gelen talep durağanlığı gibi dışsal ve devletin rolünün artmasına bağlı olarak oluşan yönetim başarısızlıkları gibi içsel etkenler sebebiyle, yeni ekonomiye ayak uydurmaktan yoksun, mali açıkları artmış, hizmet kalitesi kötüleşmiş, yeniliklere kapalı kalmış ve bu süre içinde hızla gelişen karayolu, havayolu gibi ulaşım alt sistemleri karşısında pazar gücünü kaybetmiş bir sektör durumuna düşmüştür (Karamanoğlu,2011).

Demiryollarının ulaştırma alanındaki üstünlüğü karayolları, boru hatları ve havayollarından gelen rekabetçi baskı sonrasında yerini pazar payı ve kâr kayıplarına bırakmış; 20. yüzyıl demiryolu politikası, bu gelişmeler doğrultusunda gelen reform ihtiyaçları sonucunda yeniden tasarlanmıştır (Gomez ve Ibanez,2004).

Demiryollarında devletin varlığı, katı regülasyon uygulamaları veya hizmetlerin doğrudan kamu kesimi vasıtasıyla yerine getirilmesi biçiminde şekillenmiştir. Kamu işletmeciliği, asıl faaliyeti taşımacılık olan demiryollarına istihdam, bölgesel kalkınma gibi diğer sosyal politikalara aracı olacak bazı mükellefiyetler getirmiştir. Desteklerin, aşırı istihdam ve kârlı olmayan şebekelerde faaliyetlerin sürdürülmesi gibi durumların yol açtığı zararları yeterince karşılayamaması nedeniyle demiryolları, ekonomik anlamda oldukça büyük zarara uğramıştır (Gomez ve Ibanez, 2004).

Demiryolu sektöründe başarılı bir reformun içerisinde; mevcut demiryolu kaynaklarının aktif kullanımının geliştirilmesi ve ürün ve hizmet yenilemeleri ile birlikte çeken çekilen araçlar ve altyapı yatırımları için elverişli isteklendirme işleyişinin oluşturulması, demiryolu işletmecilerinin, pazar gücünün kötüye kullanımından sakınılması, sektörün devlet üzerindeki mali yükünün azaltılması gibi amaçlar vardır. Bu doğrultuda yeniden yapılandırma çalışmalarında kesin olarak cari açıkların düşürülmesi, etkinliğin artırılması ve hizmet kalitesinin yükseltilmesi hedeflenmektedir (Karamanoğlu,2011; Ordover ve Pittman,1994).

Reform süreçlerinin ilerleyişi ülkedeki bulunan demiryollarının durumu, ülkenin coğrafi, ekonomik ve demografik yapısı ile ulaşım ihtiyacına göre farklılık arz etmektedir. Reformların ülkeler düzeyinde gelişimine baktığımızda, Avrupa devletleri ve Avustralya'da dikey ayrışmanın özelleştirmeden daha fazla ağırlık kazandığı, Latin Amerika ve Japonya'da ise özelleştirme ve ulaşım uygulamalarının beraber hayata geçirildiği görülecektir. Amerika kıtasında demiryolu hizmetleri eskiden bu yana özel sektör aracılığıyla yürütülmektedir. ABD ve Kanada gibi ülkelerde ise sektörün diğer ulaşım alt sistemleri karşısındaki rekabetçi gücünü geri kazanması amacı ile bağımsız karar alma mekanizmalarının kurulması gerektiğinden dolayı katı regülasyon uygulamaları bırakılarak deregülasyon uygulamalarına geçilmiştir (Karamanoğlu,2011; Gomez ve Ibanez,2004).

Reformların başarısı, devletin ulaştırma politikasında demiryollarına verdiği ağırlık ve önem ile demiryolu finansman açıklarının büyüklüğü ile ilintilidir. Günümüze kadar gerçekleşen ülke uygulamaları da dikkat ile incelendiğinde görülecektir ki, demiryolu reformları hakkında yapılacak en doğru saptama, belirlenen hedeflere ulaşmak için önerilecek tek bir çözüm yolunun bulunmadığıdır (Karamanoğlu,2011;Thomson,1994).

\subsubsection{Rekabet Türü Modelleri}

Demiryolu sektöründe rekabetin iki türü olduğu söylemek yanlış olmayacaktır. Bunlardan birincisi, şuanda tekel konumdaki demiryollarının da karşı karşıya olduğu ulaşım alt sistemleri arasındaki rekabeti izah eden intermodal rekabet. íkincisi ise bilhassa demiryolu sektörü içindeki ulaştırma etkinliklerinde rekabetin oluşturulmasını öngören sektör içi rekabettir. Bu çalışma kapsamında sektör içi rekabet modeli incelenecektir.

\subsubsection{Sektör İçi Rekabet}

emiryolu sektörü içinde rekabet, pazar içi veya pazar için rekabet şeklinde olmak üzere 2 türdedir. Pazar içi rekabet ile sektör içi rekabet birbirinden farklı kavramları nitelendirmekte; sektör içi rekabet, pazar içi rekabeti de içine alacak biçimde kullanılmaktadır. Pazar içi ve pazar için rekabet sistemlerinin ortak noktası demiryolu 
hizmetlerinde özel sektör katılımının uygun zemin oluşturmaktır (Kabasakal ve Solak,2009; Karamanoğlu,2011;OECD,2005;OECD;1997;ESCAP,2003)

\subsubsection{Yatay Yapılanma Modeli}

Yatay yapılanma modelinde, farklı demiryolu girişimleri mülkiyeti veya kontrolünde birden fazla demiryolu ağı mevcuttur. Her bir girişim içinde altyapı ve işletme etkinlikleri birlikte yürütüldügünden dolayı dikey ayrışma mümkün değildir. Bu sebeple, yatay yapılanma modeli, dikey yapılanma modellerinden farklı olarak dikey bütünleşik girişimler arasında rekabete olanak sağlamaktadır (OECD,2005).

\subsubsection{Dikey Yapılanma Modeli}

Demiryolu şebekelerinde dikey yapılanma modeline yönelilerek altyapı etkinliklerinden farklı olarak doğal tekel niteliği göstermeyen işletme etkinliklerinin de rekabete açılması gerektiğini belirtmekte yarar vardır. Dikey yapılanma modeli altında, demiryolu altyapı etkinlikleri tek elden yönetilmeye devam etmekte, sadece taşımacılık hizmeti verebilecek bağımsız demiryolu işletmelerinin pazara girişine olanak sağlanmaktadır. İşletmeler, altyapıyı kullanabilmek amacı ile altyapı işletmecilerine kullanım hakkı ücreti vermektedirler.(Karamanoğlu,2011;OECD,1997).

Dikey yapılanma modellerinden organizasyonel ayrım modelini irdelenecek olursak; organizasyonel ayrım modelinde, bağımsız demiryolu işletmelerinin pazara girişine izin verilirken yerleşik firmanın dikey bütünleşik yapıda bırakılması ile rekabet ortamı sağlanmaya çalışılmaktadır. Ancak organizasyonel ayrım modelinde, yerleşik firmanın alt pazardaki rakiplerinin faaliyetlerini zorlaştırmaya yönelik ayrımcı uygulamalar ve altyapı faaliyetlerindeki pazar gücünü rakip firmayı olumsuz yönde etkileyecek şekilde kullanması gibi olası riskler bulunmaktadır. Bu durumun önüne geçilebilmesi için erişişim ücretlendirmesi ve kapasite tahsisi gibi çoğu konuda ayrıntılı biçimde düzenleyici önlemlerin alınması gerekmektedir. Bir diğer tür olan kurumsal ayrım modeli irdelendiğinde ise; kurumsal ayrım modeli, altyapı sahibinin demiryolu ulaşım hizmetlerini sunmasına izin verilmediği durum olarak tanımlanmaktadır. Kurumsal ayrımın, altyapı firmasını ayrımcı davranmaya iten sebeplere imkan vermeyen ve regülasyon yerine daha çok rekabete imkan tanıyan bir model olduğu görüşü hakimdir. Diğer taraftan, kurumsal yapılanma altında yeni girişlerin yaşanmadığı durumlarda, demiryolu hizmetlerinde altyapı etkinliklerindeki tekel gücüne bir yenisi daha eklenmesi olasılığı da bulunmaktadır. Altyapı-işletme etkinliklerinin iki ayrı tekel firma tarafından yürütülüyor olması dolayısıyla taşıtıcıların ödeyecekleri taşıma hizmeti fiyatı, yatay yapıdaki tekel firmanın belirleyeceği fiyattan yüksek olacaktır (Pittman,2005;Pittman,2002).

\subsubsection{Türkiye Açısından Demiryolu İşletmeciliği Rekabet Uygulamaları}

Türkiye'de demiryollarında serbestleşme ve yeniden yapılanma süreci uzun yıllardan beri süregelen bir tartışma konusu olmuştur. Uzun süre gelen çalışmalardan sonra, son olarak 1.5.2013 tarihli ve 28634 sayılı Resmi Gazete' de yayımlanarak, 24.4.2013 tarihli 6461 sayılı Türkiye Demiryolu Ulaştırmasının Serbestleştirilmesi Hakkında Kanun yürürlüğe girmiştir.

6461 sayılı Türkiye Demiryolu Ulaştırmasının Serbestleştirilmesi Hakkında Kanun sonucunda önceden altyapı işletmecisi olan TCDD ye, Altyapı Yapım, Altyapı Bakım ve Şebeke Yönetimi görevleri verilmiştir. TCDD’nin demiryolu altyapı işletmecisi olarak yeniden yapılandırılması, TCDD Bağlı Ortaklığı olan TCDD Taşımacılık A.Ş’nin kurulan yük ve yolcu taşımacılığı yapılması ile özel sektöründe yük ve yolcu taşımacılığı yapmasının önünün açılması, demiryolu altyapı işletmecisi veya tren işletmecisi olarak kamu tüzel kişileri ile şirketlerin yetkilendirilmesi gibi hususlar düzenlenmiştir (6461 sayılı kanun).

6461 sayılı Türkiye Demiryolu Ulaştırmasının Serbestleştirilmesi Hakkında Kanun'a göre TCDD’nin bağlı ortaklığı statüsünde ticari esaslara göre yük ve yolcu taşımacılığı hizmeti yapmakla görevli anonim şirket olan TCDD Taşımacılık A.Ş, Lojistik, Yolcu Hizmetleri ve Araç Bakım olmak üzere üç ana iş birimine ayrılmaktadır (6461 sayılı kanun).

Erişim koşullarını düzenleme ve uygulamasını denetleme görevi ise 655 sayılı KHK'ya göre DDGM' ye verilmiştir. 655 sayılı KHK'ye göre, DDGM ayrıca demiryolu altyapı erişim ücretleri ile taşımacılık etkinliklerine ilişkin gerektiğinde taban ve tavan ücretlerinin belirlemek ve uygulamasını teftiş etmek ile yükümlüdür. 
Bu yapılanma çalışmaları ile altyapı idaresi ve taşımacıık hizmetlerine ilişkin etkinlikler ayrı tüzel kişilikler tarafından yönetilecektir. TCDD dikey bütünleşik yapıda bırakılarak organizasyonel ayrım yöntemi ile sektörde rekabet ortamı oluşturabilmek için yukarıda adı geçen kanunlar ve KHK' ler çıkarılmıştır.

\section{SONUÇ VE ÖNERILER}

Bu çalışma kapsamında günümüzde giderek bir ihtiyaç haline gelmiş olan demiryolu sektöründeki rekabet modelleri incelenmiş ve Türkiye'ye uyarlanması değerlendirilmiştir.

Türkiye Cumhuriyetinde 2014 yılı verilerine göre yük taşımacılığı hacminin \%89,5 lik bir kısmını karayolu oluşturmaktadır, bunun yanında demiryolu \%4,6 denizyolu ise \%5,9 luk kısmını oluşturmaktadır. Ülkemizde ki yük taşımacılığı bakımından demiryolunun diğer ulaştırma türlerine göre oldukça düşük paya sahip olmasının nedeni geçmişten bu yana gelen plansız uygulamalardan kaynaklanmaktadır. Aynı şekilde Türkiye Cumhuriyetinin dış ticaret hacmine bakıldığında demiryolunun diğer taşıma türleri yanında en düşük hacime sahip olduğu görülecektir. Nitekim Devlet Planlama Teşkilatının her beş yıllık kalkınma planlarında bu duruma değinilmiş fakat ne yazık ki süre gelen yanlış düzeltilememiştir.

1983-1993 yıllarını kapsayan Ulaştırma Ana Planında ( UAP), 1980 yılında \% 68,5 civarında olan karayolu yük taşımacılı̆̆ının 1993 yılına gelindiğinde \%36 ya düşürülmesi, \%9,9 olan demiryolu yük taşımacılığııın ise $\% 27,5$ a çıkarılması planlanmıştır. Ulaştırma sistemimizin iyileştirilmesi yönünde bir milat olarak öngörülen UAP 1986 yılından sonra da uygulamadan anlaşılamaz bir neden ile kaldırılmışır.

2035 yııına kadar $31000 \mathrm{~km}$ hattın tamamlanması planlanmakta ve demiryolu yük taşımacılığı hacminin \%15 mertebesine ulaştıııması hedeflenmektedir. Lakin Türkiye'nin coğrafi özelliklerine bakıldığında AB ülkeleri ile çok benzer olması sebebiyle planlama çalışmalarının da benzerlik göstereceği aşikârdır. Bu sebeple hedeflenen bu \% 15 lik değerin, AB de olduğu gibi en az \% 25 - \%30 lar seviyesine çıkartılması gerekmektedir. Nitekim demiryolu yük taşımacılığını ülke içinde yaratabileceği katma değer potansiyeli düşünüldüğünde bu çalışmalara vakit kaybetmeden başlanılmasında yarar vardır.

Türkiye Cumhuriyetinin coğrafi ölçütlerine göre dikey yapılanma modelini tercih etmesi daha doğru olacaktır. Nitekim hukuki alt yapısı 2013 yılında tamamlanması ile birlikte dikey yapılanma modeline geçilmiştir. Lakin dikey yapılanma modellerinden kurumsal ayrım ( tam dikey ayrışık yapı) yerine organizasyonel ayrım ( dikey erişim) modelini seçilmiştir. Organizasyonel ayrım modeli kapsamında yerleşik firma olan TCDD' nin dikey bütünleşik yapısı korunmakla birlikte diğer demiryolu firmalarının pazara girmesi planlanmaktadır. Bu model, yatay yapılanma ile kurumsal ayrım modeli arasındaki bir model türüdür. Bu modelin seçilmesindeki asıl neden yukarıda da bahsedildiği üzere iletişim sorunlarından kaynaklı ekonomik kayıpların giderilebileceğinin düşünülmesidir. Fakat bu modelin tercihindeki en büyük sorun, hakim firma olan TCDD ye yönelik ayrımcı faaliyetlere yönelebilme olasılığıdır. Bu durum sektöre dışarıdan girecek firmaları olumsuz yönde etkileyecek ve uzun bir süre telafisi mümkün olmayan ekonomik zararlara yol açacaktır. Bu algıyı daha baştan kırmak ve ayrımcı davranışlara yönelebilecek unsurları tamamen devre dışı bırakmak için esasen Türkiye'nin kurumsal ayrım modeline yönelmesinde fayda vardır.

Kurumsal ayrım modelinin hayata geçirilebilmesi için işletmeden kaynaklanan koordinasyon sorunları giderilmeli, işletme faaliyetlerini yürütmesi planlanan TCDD Taşımacılık A.Ş özelleştirilmelidir. Bununla birlikte Demiryolu Düzenleme Genel Müdürlüğünün, Türkiye Cumhuriyeti Ulaştırma, Denizcilik ve Haberleşme Bakanlığına bağlı bir kurum olmaktan çıkarııp ilişkili bir üst kurul olması yönünde çalışmalar başlatılmalıdır. Bu sayede düzenleyici bir kurum olarak sektöre yönelik daha bağımsız karar alma mekanizması oluşturulacaktır.

Tabi ki bu bahsedilen modellerden hepsinin avantajlı yönleri olduğu gibi dezavantajlı yönleri de vardır, lakin bu modellerden Türkiye' nin rasyonal ve ekonomik şartlarına göre en uygun olanı seçmesi gerekmektedir ve uzun vadede rekabet ortamının tam anlamıyla sağlanabilmesi düşünülmelidir. Bu perspektifte bakıldığında kurumsal ayrım modelinin Türkiye için daha doğru bir model olduğu görülecektir ve demiryollarından elde edilen verimlilik artacaktır. 


\section{REFERENCES}

Kabasakal, A., Solak, A. O. (2009, Aralık). Demiryolu Sektörünün Rekabete Açılması. Sosyal Bilimleri Dergisi, 25: 27-34.

Cantos, P. and Campos, J. (2005). Recent Changes In The Global Rail Industry: Facing The Challenge Of Increased Flexibility, European Transport,29:1-21.

Özcan, İ. Ç. (2006, Aralık). Demiryolu Ulaştırmasında Kamu-Özel İşbirliği Modeli ve Türk Tecrübesi. Uluslararası Demiryolu Sempozyumu Bildiriler Kitabı. Cilt. 2,: 1058

Duman, ì. (2006, Aralık).Demiryollarının yeniden yapılanma ihtiyacı ve TCDD’ deki Gelişmeler.Uluslararası Demiryolu Sempozyumu Bildiriler Kitabı, Cilt. 2: 1042.

Bayraktutan, Y., Özbilgin. (2014, 15-17 Mayıs). Raylı Yük Taşıma Sistemlerinin İktisadi Avantajları ve Türkiye İçin Bir Değerlendirme. III. Ulusal Lojistik ve Tedarik Zinciri Kongresinde sunuldu, Trabzon.

McCullough, G. J. (2006) . U.S. Railroad Efficiency: An Economic View in Conference Proceedings XX: Research to EnhanceRail Network Performance. Transportation Research Board of the National Academies, Washington, DC: 2-21

http://www.emo.org.tr/ekler/7ccd0ae17c4c6a8_ek.pdf?dergi=920: Son Erişim Tarihi: 09.03.2016

Ulaştırma Hizmetleri DemiryoluTaşımacılığı,MEB,2011,Ankara:5-6

Karamanoğlu, C. (2011). Demiryolu Sektöründe Yapısal Reformlar ve Rekabet: Serbestleşme Öncesi Türkiye İçin Öneriler, Uzmanlık Tezi, Rekabet Kurumu, Ankara: 11-26

Gomez-Ibanez, J. A. (2004). Railroad Reform: An Overview Of The Options. Paper to be presented at the Conference on Railway Reform Rafael del Pino Foundation, Madrid: 2-19.

Thomson, L. S. (1997). World Bank Support for Developing Railways of the World. Japan Railway\&Transport Review, 2-15.

Ordover, J., Pittman, R. (1994). Restructuring the Railway for Competition. Paper to be presented at the OECD/World Bank Conference on Competition and Regulation in Network Infrastructure Industries, Budapest:1-3

OECD. (2005). Structural Reform in the Rail Industry. Organisation for Economic Co-operation and Development, 7-57.

OECD. (1997). Railways: Structure, Regulation and Competition Policy: 9-249.

ESCAP. (2003). The Restructuring of Railways. New York,: Economic And Social Commission For Asia And The Pacific: 19-20.

http://www.resmigazete.gov.tr/eskiler/2013/05/20130501-1.htm: Son Erişim Tarihi: 09.03.2016

Pittman, R. (2005). Structural Separation to Create Competition? The Case of Freight Railways, Review of Network Economics, 4 (3):181196.

Pittman, R. W. (2002). Chinese Railway Reform and Competition: Vertical or Horizontal Restructuring ?.US Department of Justice Antitrust Division, Economic Analysis Group Working, 02 (2): 7-12. 